\title{
Growing to be Independent in an Interdependent Culture: A Reflection on the Cultural Adaptation of Creative and Expressive Arts Therapy in an Asian Global City
}

\author{
在相互依存的文化中成长为独立的人：对创造性和表达性艺术治疗于亚洲国际 \\ 都会中的文化适应之反思 \\ Rainbow Tin Hung Ho \\ The University of Hong Kong, Hong Kong, China
}

\begin{abstract}
Hong Kong is culturally unique. Although its Chinese culture is ingrained, it is also deeply saturated by Western culture due to its long history of Western governance. When considering this in relation to personal and cultural self-construal, the question arises of whether people in Hong Kong tend to view themselves as more independent or interdependent. This question is important for creative and expressive arts therapists because self-construal affects an individual's motivations for emotional expression and self-development in relation to others, which then affects how arts therapists can encourage individuals to express emotions and grow towards independence and self-actualization. Various clashes may arise between independent and interdependent cultures due to their different life emphases. Therefore, when adapting the skills and knowledge of creative and expressive arts therapy to an interdependent culture, full attention must be paid to supporting individuals in such a culture to discover the optimal balance of the self in relation to others and the community at large, while also considering the dynamic changes in the culture itself over time.
\end{abstract}

Keywords: Independent self, Interdependent self, Chinese, Creative and expressive arts therapy, Hong Kong

\section{摘要}

香港具有独特的文化。尽管中国文化根深蒂固，由于长时间受到西方的统治，香港文 化亦受到西方文化的深度熏陶和浸润。基于这点，当我们探讨个体和文化自我观念的 建构时，我们会遇到「香港人到底是倾向于将自己视为较独立的，还是较相互依存」的命 题。这个命题对创造性和表达性艺术治疗很重要，原因是自我观念会影响个人尤其是与 人相处时的情感表达和自我发展的动机和取向，对艺术治疗师能够如何鼓励个人表达情 感以让个体朝着独立和实现自我的方向成长有着重要影响。还有，生活重点在人生的不 同阶段会有所不同，独立和相互依存文化之间的角力或会造成各种冲突。因此，于相互 依存的文化下应用创造性和表达性艺术治疗的技巧和知识时，我们必须加倍注意如何让 个人在发展个体自我的同时能够与他人和整个社会状况取得平衡，以符合相互依存的文 化环境; 并同时须考虑到文化本身亦会随着时间不断变化而出现各种改变。

关键词 : 独立的自我，相互依存的自我，中国，创造性和表达性艺术治疗，香港 


\section{Culture, Well-Being, and Arts Therapy}

Hong Kong has positioned itself as one of Asia's foremost world cities. According to the Global Cities Index, Hong Kong is ranked number five in the list of the world's most global cities, behind New York, London, Paris, and Tokyo (Peterson, Hales, Mendoza, \& Dissibourg-Free, 2019). Despite this high position and having the highest number of international schools, the most air freight, and the top global services firms in the world, $92 \%$ of the Hong Kong population are Chinese (Census and Statistics Department, 2018). Moreover, the Chinese culture is still dominant in Hong Kong even though it was governed by the British for 156 years (from 1841 until 1997). The interwoven impacts from both Western and Eastern cultures over the years in Hong Kong have created a unique context in which individuals may have very different views and behaviors.

Well-being is a global concern-regardless of culture and region. However, culture has a direct effect on an individual's definition of well-being because it shapes values and life goals (Christopher, 1999; Markus \& Kitayama, 1998). Culture also shapes a person's self-identity and behavior as well as affects the way that an individual expresses emotions and relates to others and the community at large. Since creative and expressive arts therapists work with emotional expression to help individuals develop a better relationship with the self, others, and the community - which ultimately contributes to the well-being of the individual - it is vital to have a deeper understanding of the impacts of culture on both the individual and the community.

Self-actualization, an important topic in humanistic psychology (Maslow, 1954) and cardinal to modern psychotherapy, also relates to well-being as the pursuit of excellence and enjoyment is a key element of developing a fulfilling and satisfying life (Ellis, 1991). Empirical research further demonstrated this relationship by showing that self-actualization is a component of well-being (Compton, 2001; Kim, Kasser, \& Lee, 2003). However, the concept of self-actualization came from Western psychology (Maslow, 1954) and focuses on self-development for fulfilling the highest level of needs in individual's development rather than an emphasis on the societal relationships and harmony, which are important in traditional Confucianism in Eastern culture. In this regard, a reconsideration of cultural self-construal in relation to creative and expressive arts therapy becomes especially meaningful in a city where Eastern and Western cultures have been juxtaposed for years.

\section{Culture and Emotional Expression}

The notions of independent and interdependent self-construal were originally coined by Markus and Kitayama (1991) and have since been used by social psychologists and cross-cultural psychologists to reflect an individual's concept of the self and relationships with others and the wider society in individual and collectivistic cultures (Triandis, Bontempo, Villareal, Asai, \& Lucca, 1988). Independent self-construal emphasizes individual needs and autonomy, while interdependent self-construal is more concerned with social harmony, tending to control an individual's personal needs and behavior in favor of the demands of others and the community (Markus \& Kitayama, 1991; 
Triandis, 1995). It has been stated that Western cultures tend to be individualistic, with Westerners therefore more independent, while Eastern cultures tend to be collectivistic, with Easterners therefore more interdependent (Markus \& Kitayama, 1991).

Studies have also found that people in independent cultures tend to express emotions more freely than those in interdependent cultures, who tend to exhibit more controlled emotional expression in favor of maintaining interpersonal or social harmony (Markus \& Kitayama, 1998). This relationship has been further supported by recent neuroscientific research indicating the effect of being embedded in a specific culture on regulating the subcortical affective system in the brain (Özkarar-Gradwohl, 2019). For instance, in a study of expression of positive affect on population samples from United States and Turkey, American participants scored higher than their Turkish counterparts (Özkarar-Gradwohl et al., 2014). In the study, American culture was regarded as independent culture, whereas Turkish culture was considered as a bridging culture with coexisting independency and interdependency (Kagıtçıbaşı, 2005). These findings suggested that independent cultures encouraged the expression of strong positive affect, whereas interdependent cultures encouraged its expression only up to a limit to avoid disturbing the harmony of the group. Nonetheless, the distinction between independent and interdependent cultures has been demonstrated to be less clear in recent decades. Cross-cultural studies have revealed that people in interdependent cultures (i.e., Japan), independent cultures (i.e., the United States and Germany), and even bridging cultures (i.e., Turkey), shared similar interdependent features in regard to emotional expression (Özkarar-Gradwohl, 2019). Different combinations of independency and interdependency have also been found in different cultures (Vignoles et al., 2016). Özkarar-Gradwohl and colleagues (2020) demonstrated this in a recent study among Japan, Turkey, and Germany, in which interdependent self-construal was found to decrease from East to West, whereas independent self-construal did not show a corresponding westward increase.

As the expression of emotions can help an individual give vent to his or her feelings and support further communication and self-understanding, it has been one of the central topics of creative and expressive arts therapy. However, based on the fundamental differences in emotional expression in different cultural settings, the question arises of to what extent we ought to encourage individuals in interdependent cultures to express their emotions freely while maintaining cultural appropriateness. Should therapists always encourage individuals to pay more attention to the self and express their emotions, or should they consider the need to be less expressive when interpersonal harmony is at risk?

\section{Individuation and Separation in an Interdependent Culture}

Growing to be independent is an important element of an individual's development and relates closely to the processes of self-actualization. Related to this, individuation, is another concept that refers to the process of maturing and being able to leave one's parents or original family and live on one's own, a process also called separationindividualization (Mahler \& Laperriere, 1965). In Western psychology, individuation 
is an important growth and maturation journey because of the emphasis placed on independence by the culture and society; collectivistic cultures, on the other hand, tend to place greater emphasis on relationships and interdependency. This is also exemplified in daily life, with studies finding prolonged breastfeeding and co-sleeping to be more common in collectivistic cultures (Mindell, Sadeh, Kohyama, \& How, 2010; Özkarar-Gradwohl, 2019; Shimizu, Park, \& Greenfield, 2014). However, the process of separation might not play an equally important role in an interdependent culture, such as the Chinese culture, as in an independent culture, such as some Western cultures. Essame (2009) has already pointed out that, in many Asian cultures, existing as an individual is not the core issue; rather, "a self deeply integrated with the group" may be more important (p. 95). In this regard, a question arises for therapists as to what extent individuals should be encouraged to focus on the individuation and separation process, or more specifically, on the aim of becoming more independent in a context where it may not be culturally appropriate.

The questions I ask here are not purely theoretical. Similar questions might have been asked by other cross-cultural psychologists and creative arts therapists. Given that creative and expressive arts therapies, which have an important focus on supporting individuals' growth and development, are increasingly popular in Hong Kong, and the general Asia area, these questions become significantly imminent. I have been working as a creative and expressive arts therapist in Hong Kong in the past 18 years and have witnessed individuals' struggles on realizing that their independent self is trying to emerge from the interdependent culture of their families and the wider society. For example, sexual abuse survivors, whose abusers were family members, struggling over their disclosure of the issues and their decision over whether to leave the house in which they were abused. I have also witnessed struggles over the emotional expression of spouse or adult child caregivers to close family members suffering from severe illnesses; they wrestle with whether they can express their emotions honestly or show enjoyment of anything without feeling guilty for their suffering family members. Similarly, struggles can often be seen over the decision to stay or leave the family for victims of domestic violence, and people with interpersonal conflicts, etc. When the desire to fulfill personal needs and interests does not chime with other people's interests and/or the need to maintain harmony in the family or in society, conflict and struggle usually occur. Essame (2009) has mentioned the importance of filial piety in Asian cultures and how the nonverbal and creative process in art therapy can be particularly helpful for avoiding direct confrontation within a family or a community. She also suggested art therapy in Asia "may start as individual to build the therapeutic alliance and assess further the individual needs and processes, but the end aim may often be to integrate the client into a group" (p. 98), indicating the importance of the consideration of the appropriate balance between independence and interdependence in arts related intervention in Asia.

The recent social unrest in Hong Kong also reflects such a dilemma, albeit in different ways, as some people are longing to be more independent and to have a unique identity, whereas other parts of society may not hold the same views or values. Fights among people with different views have disrupted the social harmony, and conflicts exist 
within families, workplaces, and the community. Without taking a political perspective on this event, my concerns are more about its relation to the potential conflicts between the independent self and the interdependent self in people in this culturally mixed city and how this does and will inform creative and expressive arts therapy. The broader issue is relevant not only to Hong Kong but also to China as a whole. A recent study of students in mainland China revealed that the personal self and relational self had a robust relationship with subjective well-being, whereas the collective self did not show such a correlation (Du, King, \& Chi, 2017). The authors of that study suspected that the results might be due to the lower priority given to the collective self in their sample. This might imply that collectivistic culture and its related self-construal are changing, if not diminishing or fading, in modern Chinese society, which raises the question of how psychotherapy should make appropriate adjustments for this change in self-construal in relation to changes in culture when dealing with issues related to the self and others.

\section{Cultural Adaptation of Creative and Expressive Arts Therapy}

Adapting creative and expressive arts therapy to Chinese society and culture requires full attention to how traditional culture interacts with modern development. Modern development here refers to the influence of westernization of self-concepts and ideology, which is being accelerated by high-speed and high-intensity information exchanges through modern technology and social media. The Western concept of independence is highly valued in modern society, whereas the traditional Chinese cultural emphasis on harmony and solidarity should not be neglected as individuals cannot survive or thrive alone. We are inherently social and need forms of attachment to others. Research on quantum physics has already found that even though we appear physically separated, we stay connected invisibly through electromagnetic fields, and our behaviors might affect others even at this level (Liboff, 2017). In this regard, we may need to think deeply about how we ought to support people to become independent or actualize themselves in a culturally appropriate way.

Interestingly, both arts therapists and non-arts therapists have suggested that nonverbal approaches should be more appropriate for developing culturally specific psychotherapy, particularly when social harmony is at risk due to overly expressed individual concerns or emotions (Essame, 2009; Özkarar-Gradwohl, 2019). Arts-based therapies, which use fewer verbal exchange and emphases on self-reflection, should have greater safety and be more suitable for this context. Nevertheless, even within Eastern cultures or Asian cultures, there are unique combinations of dependence and interdependence in affective expression and self-construal. Therefore, special attention has to be paid to an individual's and his or her family's unique cultural background when adapting and applying psychotherapy or arts therapies.

\section{Optimal Combination of Independence and Interdependence in Hong Kong}

People in Hong Kong have a unique culture due to the deep influences from both the East (Chinese) and the West (British) governance history as well as the different 
political contexts the different generations may have experienced. Although it may be too arbitrary and overly simplified to categorize more than seven million people in Hong Kong, three distinct generations could be identified according to the different political, historical contexts of the island. The older generation, who were born before the 1950s, are mainly immigrants from mainland China and have a strong sense of traditional Chinese culture. The middle generation, who were born between the 1960s and the 1990s, mostly grew up in Hong Kong during the British governance. They are more westernized but are still influenced by Chinese culture, mainly by the early generation. The young generation, who were born after the 1990s, are strongly affected by different cultures from all over the world due to the advance in information technology. Specifically, owing to the return of sovereignty from British to China, civic-based identity, or "localism," has become stronger in young generation (Tsang, 2003; Veg, 2017). Young people in Hong Kong tend to recognize themselves as Hong Kongers, rather than as pan-Chinese (Veg, 2017).

These three generations may have very different senses of independent self and collective self due to their unique cultural background and historical-political contexts. It will be interesting to know how different generations with different independent self and collective self-construal can stay together and how different combinations of selfconstrual contribute to their individual well-being or well-being as a whole community.

A recent study on undergraduate students in a major city in China revealed that individuals who could adapt to both the independent and interdependent forms of self-construal exhibited the highest levels of subjective well-being, indicating an optimal level of individual adaptation (Yu, Zhou, Fan, Yu, \& Peng, 2016). The authors suggested that "cultivating a sense of self and collective worth, respect, and superiority in undergraduate is important for enhancing their well-being" (p. 217). This recommendation may be relevant to the Hong Kong context, even though the particular history of Hong Kong means that the collective self of Hong Kong people may differ from that of mainland China and also differ from generation to generation. In fact, what does collectivistic culture means to people in Hong Kong, and what is the identity of a Hong Konger? These are important and meaningful questions that we should be aware of without collapsing psychotherapy into politics. Lastly, as therapists, it is important for us to acknowledge of our cultural values and their changes over time alongside understanding of the unique cultural makeup of the individuals with whom we work.

\section{Conclusion}

Improving clients' subjective well-being and supporting their growth and selfactualization are important purposes of creative and expressive arts therapy regardless of culture. Although these purposes should not be identified as right or wrong in any culture, we need to be fully aware of the potential conflict between the more Western independent cultural norm of paying more attention to the self and the more Eastern interdependent cultural norm of putting others first. To find the optimal balance between developing the dependent self and facilitating an individual's self-actualization without damaging the interdependent self and culture, creative and expressive arts therapists 
need to develop a sensitivity to culture and its dynamic changes over time. In general, knowledge, sensitivity, and flexibility are of central importance to effective, ethical, and culturally sensitive therapeutic practice.

\section{About the Author}

Rainbow Tin Hung Ho, University Professor, Dance Movement Therapist, Expressive Arts Therapist, Somatic Movement Therapist, Group Psychotherapist, Certified Movement Analyst, The University of Hong Kong, Hong Kong SAR. Email: tinho@hku.hk

\section{References}

Census and Statistics Department. (2018). Hong Kong 2016 Population. Retrieved [December 2, 2019], from https://www.had.gov.hk/rru/english/info/info_dem.html.

Christopher, J. C. (1999). Situating psychological well-being: Exploring the cultural roots of its theory and research. Journal of Counseling and Development, 77(2), 141-152.

Compton, W. C. (2001). Toward a tripartite factor structure of mental health: Subjective well-being, personal growth, and religiosity. Journal of Psychology, 135(5), 486-500.

Du, H. F., King, R. B., \& Chi, P. L. (2017). Self-esteem and subjective well-being revisited: The roles of personal, relational, and collective self-esteem. Plos One, 12(8), e0183958.

Ellis, A. (1991). Achieving self-actualization-The rational-emotive approach. Journal of Social Behavior and Personality, 6(5), 1-18.

Essame, C. (2009). Collective versus individualist societies and the impact of Asian values on art thearpy in Singapore. In D. Kalmanowitz, J. S. Potash, \& S. M. Chan (Eds.), Art therapy in Asia: To the bone or wrapped in silk (pp. 91-101). London and Philadelphia, PA: Jessica Kingsley Publishers.

Kagıtçıbaş1, C. (2005). Autonomy and relatedness in cultural context. Journal of Cross Cultural Psychology, $36,403-422$.

Kim, Y., Kasser, T., \& Lee, H. (2003). Self-concept, aspirations, and well-being in South Korea and the United States. Journal of Social Psychology, 143(3), 277-290.

Liboff, A. R. (2017). The electromagnetic basis of social interactions. Electromagnetic Biology and Medicine, 36(2), 177-181.

Mahler, M. S., \& Laperriere, K. (1965). Mother-child interaction during separation-individuation. Psychoanalytic Quarterly, 34(4), 483-498.

Markus, H. R., \& Kitayama, S. (1991). Culture and the self-implications for cognition, emotion, and motivation. Psychological Review, 98(2), 224-253.

Markus, H. R., \& Kitayama, S. (1998). The cultural psychology of personality. Journal of Cross-Cultural Psychology, 29(1), 63-87.

Maslow, A. (1954). Motivation and personality. New York: Harpers.

Mindell, J. A., Sadeh, A., Kohyama, J., \& How, T. H. (2010). Parental behaviors and sleep outcomes in infants and toddlers: A cross-cultural comparison. Sleep Medicine, 11(4), 393-399.

Özkarar-Gradwohl, F. G. (2019). Cross-cultural affective neuroscience. Frontiers in Psychology, 10.

Özkarar-Gradwohl, F. G., Narita, K., Montag, C., Panksepp, J., Davis, K. L., Yama, M. \& Scherler, H. R. (2020). Cross-cultural affective neuroscience personality comparisons of Japan, Turkey and Germany. Culture and Brain, 8, 70-95. https://doi.org/10.1007/s40167-018-0074-2.

Özkarar-Gradwohl, F. G., Panksepp, J., İçöz, F. J., Çetinkaya, H., Köksal, F., Davis, K. L., \& Scherler, N. (2014). The influence of culture on basic affective systems: The comparison of Turkish and American norms on the affective neuroscience personality scales. Culture and Brain, 2(2), 173-192.

Peterson, E., Hales, M., Mendoza, P. A., \& Dissibourg-Free, N. (2019). A question of talent: How human capital will determine the next global leaders. 2019 Global Cities Report. Retrieved [December 3, 2019], from https://www.atkearney.com/global-cities/2019. 
Shimizu, M., Park, H., \& Greenfield, P. M. (2014). Infant sleeping arrangements and cultural values among contemporary Japanese mothers. Frontiers in Psychology, 5, 718. doi: 10.3389/fpsyg.2014.00718.

Triandis, H. C. (1995). Individualism and collectivism. Boulder, CO: Westview Press.

Triandis, H. C., Bontempo, R., Villareal, M. J., Asai, M., \& Lucca, N. (1988). Individualism and collectivism-Cross-cultural perspectives on self ingroup relationships. Journal of Personality and Social Psychology, 54(2), 323-338.

Tsang, S. (2003). The rise of a Hong Kong identity. In L. Fernández-Stembridge \& T. Fisac (Eds.), China Today (pp. 222-239). London: Routledge.

Veg, S. (2017). The rise of "localism" and civic identity in post-handover Hong Kong: Questioning the Chinese nation-state. China Quarterly, 230, 323-347.

Vignoles, V. L., Owe, E., Becker, M., Smith, P. B., Easterbrook, M. J., Brown, R., González, R., Didier, N., Carrasco, D., Cadena, M. P., Lay, S., Schwartz, S. J., Des Rosiers, S. E., Villamar, J. A., Gavreliuc, A., Zinkeng, M., Kreuzbauer, R., Baguma, P., Martin, M., Tatarko, A., Herman, G., de Sauvage, I., Courtois, M., Garðarsdóttir, R. B., Harb, C., Schweiger Gallo, I., Prieto Gil, P., Lorente Clemares, R., Campara, G., Nizharadze, G., Macapagal, M. E., Jalal, B., Bourguignon, D., Zhang, J., Lv, S., Chybicka, A., Yuki, M., Zhang, X., Espinosa, A., Valk, A., Abuhamdeh, S., Amponsah, B., Özgen, E., Güner, E. Ü., Yamakoğlu, N., Chobthamkit, P., Pyszczynski, T., Kesebir, P., Vargas Trujillo, E., Balanta, P., Cendales Ayala, B., Koller, S. H., Jaafar, J. L., Gausel, N., Fischer, R., Milfont, T. L., Kusdil, E., Çağlar, S., Aldhafri, S., Ferreira, M. C., Mekonnen, K. H., Wang, Q., Fülöp, M., Torres, A., Camino, L., Lemos, F. C., Fritsche, I., Möller, B., Regalia, C., Manzi, C., Brambilla, M., \& Bond, M. H. (2016). Beyond the 'east-west' dichotomy: Global variation in cultural models of selfhood. Journal of Experimental Psychology-General, 145(8), 966-1000.

Yu, X. B., Zhou, Z. H., Fan, G. H., Yu, Y. Y., \& Peng, J. X. (2016). Collective and individual self-esteem mediate the effect of self-construals on subjective well-being of undergraduate students in China. Applied Research in Quality of Life, 11(1), 209-219. 